\title{
JIMENO, Myriam; MURILLO, Sandra Liliana \& MARTÍNEZ, Marco Julián (eds.). 2012. Etnografías contemporáneas: Trabajo de campo
}

Marcos Santana de Souza

\section{(2) OpenEdition Journals}

Edição electrónica

URL: http://journals.openedition.org/aa/1226

DOI: $10.4000 /$ aa. 1226

ISSN: 2357-738X

Editora

Programa de Pós-Graduação em Antropologia Social (UnB)

\section{Edição impressa}

Data de publição: 1 dezembro 2014

Paginação: 331-338

ISSN: 0102-4302

\section{Refêrencia eletrónica}

Marcos Santana de Souza, «JIMENO, Myriam; MURILLO, Sandra Liliana \& MARTíNEZ, Marco Julián (eds.). 2012. Etnografías contemporáneas: Trabajo de campo», Anuário Antropológico [Online], v.39 n.2 I 2014, posto online no dia, consultado o 28 abril 2021. URL: http://journals.openedition.org/aa/1226 ; DOI: https://doi.org/10.4000/aa.1226

\section{(c) $(1)(9)$}

Anuário Antropológico is licensed under a Creative Commons Atribuição-Uso Não-Comercial-Proibição de realização de Obras Derivadas 4.0 International. 


\section{JIMENO, Myriam; MURILLO, Sandra Liliana \& MARTÍNEZ, Marco Julián (eds.). 2012 Etnografías contemporáneas: Trabajo de campo. Bogotá: Universidad Nacional de Colombia. Facultad de Ciencias Humanas. Centro de Estudios Sociales (CES). 316 pp. (Colección Semilleros; 4)}

Marcos Santana de Souza

UFS

A etnografia ganhou importância a partir dos trabalhos de Bronislaw Malinowski e de seus discípulos, que impulsionaram o desenvolvimento do método durante a chamada fase moderna da antropologia. Desde então, a etnografia, que inicialmente se referia à "descrição dos significados de um determinado grupo", superou os limites dessa definição e do próprio pensamento antropológico e passou a ser utilizada com maior frequência no âmbito das ciências humanas e sociais, ainda que continue sendo vista mais comumente entre antropólogos(as) como instrumento privilegiado para "fotografar" a realidade.

O livro Etnografias contemporáneas: trabajo de campo, publicado em 2012 pela Universidade Nacional da Colômbia, sob a organização dos antropólogos Myriam Jimeno, Sandra Liliana Murillo e Marco Julían Martínez, é um exemplo da relevância do método etnográfico e, sobretudo, das importantes mudanças operadas nas perspectivas metodológicas nas ciências humanas e sociais nos últimos decênios.

Composto por nove capítulos, além da introdução, o livro oferece um conjunto amplo de trabalhos irmanados pelo objetivo de apresentar análises relacionadas à pesquisa empírica, especificamente ao método etnográfico e suas potencialidades analíticas. Pela relevância social e acadêmica dos textos, e pelo caráter oportuno das abordagens, além da clara e objetiva escrita, a obra revela-se de grande importância para estimular reflexões para além dos círculos acadêmicos, seja de estudantes interessados em compreender a aplicação de métodos seja de pesquisadores em pensar sobre as escolhas metodológicas e seus efeitos nas análises dos mais diferentes objetos de investigação.

Ao focar o fenômeno da violência, a experiência social com o sagrado, os espaços de formação, como a universidade, a formulação de representações sociais sobre "heróis" nacionais, a influência dos livros de autoajuda e as reflexões metodológicas acerca do enfrentamento da violência, entre outros temas, 
o método etnográfico destaca-se na citada obra como rico instrumento para a compreensão da realidade social e para a emergência de importantes questionamentos sobre os limites e as possibilidades associadas ao fazer antropológico contemporaneamente. Figuram como exemplos desse empreendimento não apenas os processos de inserção do(a) pesquisador(a) em campo, e as implicações do seu trabalho sobre o contexto pesquisado, mas principalmente a pertinência de ferramentas metodológicas como a etnografia serem utilizadas em pesquisa sobre processos de reconstrução por parte de vítimas individuais e coletivas de episódios traumáticos.

Uma boa indicação dessa perspectiva, que apresenta a etnografia como instrumento de intervenção social, está presente no capítulo "Experiencias de violencia, etnografia y recomposión social en Colombia”, de Myriam Jimeno, Ángela Castillo e Daniel Varela. Os autores analisam as experiências de indígenas e camponeses colombianos que sobreviveram a um massacre por grupos paramilitares em 2001, de modo a compreender como o grupo reformulou o sentido da vida após o bárbaro evento. É a partir da relação entre o(a) antropólogo(a) e os sujeitos do campo, fundada em vínculo socioafetivo que aposta na memória como recurso, não apenas para a recuperação do passado, mas para a afirmação das identidades, que os autores defendem a etnografia como instrumento para a reconstrução social de eventos violentos. O método destaca-se tanto como ferramenta de produção de conhecimento quanto como forma de exercício da cidadania que se expressa na preocupação em conhecer as vozes subalternas, permitindo a construção de ações conjuntas de enfrentamento da realidade.

Em "Orden paramilitar y violencias contra las mujeres: apuntes de um análisis sociocultural”, María Jimena López León analisa, por meio do estudo das representações sociais de ex-combatentes, a violência contra mulheres em conflitos armados na Colômbia. León busca identificar os sentidos das ações, os tipos de violência empregados e o lugar do feminino e do masculino nos discursos, que tendem a assinalar, justificando abusos diversos, a guerra como um "não-lugar" para as mulheres. A relação entre método etnográfico e análise das representações sociais é um aspecto muito bem explorado pela autora, que de forma bastante lúcida ressalta as implicações do seu gênero para os resultados sobre episódios violentos contra as mulheres e, ao mesmo tempo, como elemento a favorecer que as mulheres ouvidas falassem sem maiores restrições sobre suas experiências na guerra, lócus onde o corpo feminino se destaca como "arma".

No capítulo seguinte, da antropóloga Ana Ramírez, o método etnográfico é empregado na compreensão sobre o processo de organização social de vítimas da violência do paramilitarismo e, particularmente, sobre a busca empreendida 
pelas vítimas por esclarecimento e reparação pelo Estado colombiano. Nessa perspectiva, a pesquisa investiga a experiência da Galeria da Memória como uma importante expressão do Movimento Nacional de Vítimas de Crimes do Estado (Movice). Foram analisados os recursos utilizados pelo grupo na concretização de seus objetivos, entre eles as ações da galeria, por meio do teatro como instrumento de elaboração simbólica não apenas de perdas vividas por membros do grupo, mas de suas aspirações e demandas. A Galeria apresenta-se, segundo a autora, não como um espaço de revivência de experiências dolorosas, mas de enfrentamento das lembranças de violências sofridas e por isso de luta e esperança. A etnografia possibilitou identificar as estratégias utilizadas pelo grupo para reelaborar perdas e assim forjar um sentimento de comunidade necessário ao fortalecimento da luta por reparação e justiça.

Assim, as análises dizem respeito a processos que envolvem a superação de lembranças de dor e a construção de novos horizontes de vida para as vítimas, sendo a etnografia apresentada como instrumento não apenas para a compreensão desses processos, mas, também, para um exercício de cidadania voltado à conquista de direitos. Os trabalhos mostram que ao suplantar as primeiras experiências de pesquisa, que tomavam as comunidades pelos seus elementos externos e que não raramente reduziam a importância da voz dos "nativos", a antropologia encontrou no método etnográfico um importante instrumento no processo de amadurecimento da própria disciplina com a emergência de novos objetos e enfoques. Reconhecendo a existência de outras nuances da relação entre o(a) pesquisador(a) e os contextos estudados, as pesquisas de caráter etnográfico passaram, sobretudo, a se preocupar mais diretamente com o posicionamento ético na pesquisa e com as condições e implicações da produção do conhecimento, assim como o sentido social e político do trabalho antropológico para o presente e o futuro dos grupos pesquisados.

É no campo da antropologia das emoções, um segmento que experimenta um processo de expansão recente, que o sociólogo Cristian Triana toma livros de autoajuda como objetos de investigação. O autor reflete sobre os sentidos dessa literatura na experiência contemporânea, explicando como as demandas individuais em torno do "eu" estão relacionadas à emergência de padrões sociais e culturais que explicariam a fragilidade de vínculos humanos e a necessidade de regulação do próprio desejo. Triana aposta no estudo das representações sociais como forma de compreender a conexão entre a experiência emocional dos sujeitos e padrões sociais e culturais a ela relacionados, que lhe conferem sentido como construções históricas. 
Essas questões estão presentes nos capítulos de Jimena Molano e Johana Wahanik, que investigam, respectivamente, a relação com o sagrado por meio da análise de ritos e crenças associados ao culto às almas do purgatório no Cemitério do Sul de Matatigres, na cidade de Bogotá, e a experiência subjetiva de estudantes universitários na Universidade Nacional da Colômbia. Se no trabalho de Wahanik a experiência estudantil é analisada por meio da aplicação de técnicas teatrais, no texto de Molano a etnografia evidenciou como os visitantes pensam, vivenciam e sentem o sagrado por meio de rituais que mantêm importantes conexões com outros campos da vida, em especial os que expressam as expectativas de que os mortos interfiram na dinâmica dos vivos, num contexto marcado por carências materiais e simbólicas diversas.

Já no capítulo "Una heroína sobre la red”, Sandra Murillo analisa, tendo como fontes o texto autobiográfico e relatos disponíveis na internet, as razões de Íngrid Betancourt ter se constituído como um ícone de liberdade importante para cidadãos franceses e belgas. Para isso, a autora investigou o papel da imprensa, a lógica relacionada à produção de notícias sobre violência política, as representações sociais em torno dessa violência na Colômbia e o processo de internacionalização do conflito armado. São esses fatores, além das especificidades da formação cultural francesa, que explicam a emergência da imagem de Íngrid Betancourt como heroína em contextos diversos, símbolo da maternidade na política, uma "Marianne colombiana".

Os capítulos finais do livro desenvolvem reflexões sobre a utilização da etnografia em projetos de intervenção social e sobre a metodologia a ser aplicada ao estudo de grupos juvenis violentos. Os autores Daniel Varela e Ángela Castillo exploram a pertinência das ferramentas metodológicas para o estudo da intervenção estatal, tendo como referentes empíricos um programa governamental destinado à reintegração social de pessoas e grupos armados criminosos e o sistema prisional colombiano. O texto de César Torres, por sua vez, investiga as práticas e formas de organização de torcidas violentas de futebol na Colômbia, as "barras bravas". São análises que se destacam pela capacidade de expressar as expectativas, tensões e contradições dos atores sociais em sua busca, respectivamente, do enfrentamento das dificuldades próprias ao encarceramento e da afirmação identitária juvenil com o recurso à violência. Tais análises são, inegavelmente, exemplo de mudanças importantes operadas na postura dos(das) pesquisadores(as), que passaram a reconhecer o papel dos "nativos" na explicação da própria realidade, assim como a importância de assimilar nos registros não apenas o que é "coeso", "oficial” e "legítimo", mas a dimensão pessoal, improvisada e ilegítima das práticas e dos discursos. Trata-se de uma postura que implica Anuário Antropológico/2013, Brasília, UnB, 2014, v. 39, n. 2: 331-337 
contato direto com a realidade e com os sujeitos sociais a partir de um exercício reiterado de observação e crítica (ZALUAR, 1986).

Apesar de formulados em sua maioria no interior da antropologia, os estudos que compõem o livro priorizam análises numa região de fronteira interdisciplinar, o que permite voos mais amplos, resultado de um rico debate com outras vertentes e instrumentos de investigação. Isso se revela, por exemplo, no texto da antropóloga Johanna Wahanik, que relaciona etnografia e técnicas teatrais para discutir a experiência de ser estudante da Universidade Nacional da Colômbia. Os trabalhos, de modo geral, atendem a um desafio próprio ao método etnográfico de conferir inteligibilidade a processos sociais aparentemente confusos, que se mostram inicialmente fragmentados ao(à) pesquisador(a). Para isso, os(as) autores(as), por meio da participação e observação do cotidiano dos indivíduos, recuperam significados e recompõem os fios das tramas cotidianas, oferecendo ricas imagens dos contextos e objetos pesquisados, produto de múltiplas vozes que emergem nos textos com as suas principais marcas sem negligenciar o papel do (a) antropólogo (a) na interpretação dos contextos analisados e também de seu lugar neles.

Desse processo, destaca-se o compromisso social e ético dos (das) pesquisadores (as), assim como a necessária reflexão sobre os sentidos que a pesquisa antropológica assume na superação de traumas coletivos e nos processos emancipatórios mais amplos, que envolvem não somente a formulação e efetivação de políticas públicas, mas a contestação e reivindicação em torno das ações do Estado. O livro, portanto, possui como um dos principais méritos o de expor e problematizar, em muitos momentos, as condições de produção da pesquisa e dos próprios textos: desde a obtenção dos dados e a revisão de objetivos, até as expectativas dos (das) interlocutores (as) dentro e fora do campo, não desprezando as tensões que assinalam o encontro e a interação entre as subjetividades do(da) pesquisador(a) e de seus(suas) interlocutores(as).

Em Etnografías contemporáneas, os (as) autores (as) efetivam análises em uma perspectiva holística que tem se constituído marca das pesquisas antropológicas contemporâneas. Centradas numa visão ampla da realidade, compreendem a sociedade como entidade viva, pulsante, um campo aberto a negociações e contestações da própria vida social, na qual indivíduos envolvidos pelas tensões das experiências cotidianas, a exemplo daquelas que os colocam em contato com a lembrança de violências sofridas ou cometidas, com a morte ou com o encarceramento, participam reivindicando, sobretudo, voz e reconhecimento. Os diferentes capítulos efetivam, desse modo, o que Roberto Cardoso de Oliveira (2006) chamou, em importante texto publicado inicialmente em meados dos 
anos 1990, de "unidade irredutível” na produção do conhecimento antropológico, ou seja, o ato de "ver, ouvir e escrever". Consideradas etapas fundamentais do trabalho do(da) antropólogo (a), elas formam a tríade que ainda hoje traduz o compromisso do(da) pesquisador(a) com a compreensão da realidade a ser pesquisada: despindo-se de suas certezas mais íntimas, reconhecer a alteridade em seu sentido pleno. Os (as) autores (as) do presente livro, por diferentes caminhos, mas sempre invocando o método etnográfico, ressaltam a importância do verbo "participar".

Pela rica condução dos trabalhos, que expressam os desafios, as expectativas e as ambiguidades vivenciadas pelos indivíduos no trabalho ao conferir significado a comportamentos e percepções sobre a experiência social, o livro representa mais que uma contribuição para a formação de estudantes no campo da pesquisa. Em razão dos temas e resultados apresentados, constitui uma referência importante para estudantes e professores(as) no campo das ciências humanas e sociais, bem como de profissionais, a exemplo de gestores(as) públicos(as), magistrados(as), operadores(as) de segurança pública, militantes de direitos humanos. Interessa, ainda, ao público que visa não apenas conhecer ou aprofundar o conhecimento sobre o uso da etnografia como ferramenta metodológica, mas que busca acessar um conhecimento mais amplo sobre a realidade social colombiana.

Espera-se que a obra, resultado de uma rica parceria entre jovens e experientes cientistas sociais colombianos, encontre maior visibilidade no contexto brasileiro, de modo a suscitar entre nós a ampliação não apenas do uso do método etnográfico nas ciências humanas e sociais, mas do debate sempre necessário a respeito do papel e dos efeitos de métodos e técnicas de pesquisa para a compreensão da complexidade da experiência humana. Além de permitir ver a aplicação do método etnográfico, desenvolvendo o debate interdisciplinar sobre as formas de acesso à realidade, o livro Etnografías contemporáneas: trabajo de campo é uma importante contribuição sobre os diferentes temas tratados, sem deixar de evidenciar com particular riqueza a atualidade da etnografia para a boa consecução da aventura antropológica, no seu tão desejado e difícil encontro com alteridade. 


\section{Referências bibliográficas}

CARDOSO DE OLIVEIRA, Roberto. 2006. O trabalho do antropólogo. Brasília: Paralelo 15; São Paulo: Editora Unesp.

ZALUAR, Alba. 1986. "Teoria e prática do trabalho de campo: alguns problemas". In: Ruth C. L. Cardoso (org.) A aventura antropológica: teoria e pesquisa. Rio de Janeiro: Paz e Terra. pp. 107-126. 